\title{
Detrimental and Protective Bystander Effects: A Model Approach
}

\author{
H. Schöllnbergera,1, R. E. J. Mitchel ${ }^{b}$, J. L. Redpath ${ }^{c}$, D. J. Crawford-Brown ${ }^{d}$, and W. \\ Hofmann ${ }^{a}$ \\ ${ }^{a}$ Department of Materials Engineering and Physics, Division of Physics and Biophysics, University \\ of Salzburg, A-5020 Salzburg, Austria \\ ${ }^{\text {b} A t o m i c ~ E n e r g y ~ o f ~ C a n a d a ~ L i m i t e d, ~ C h a l k ~ R i v e r ~ L a b o r a t o r i e s, ~ C h a l k ~ R i v e r, ~ O n t a r i o, ~ C a n a d a, ~ K 0 J ~}$ \\ $1 \mathrm{JO}$ \\ 'Department of Radiation Oncology, University of California Irvine, Irvine, California 92697 \\ ${ }^{\mathrm{d} C a r o l i n a}$ Environmental Program, University of North Carolina at Chapel Hill, North Carolina \\ 27599-1105
}

\begin{abstract}
This work integrates two important cellular responses to low doses, detrimental bystander effects and apoptosis-mediated protective bystander effects, into a multistage model for chromosome aberrations and in vitro neoplastic transformation: the State-Vector Model. The new models were tested on representative data sets that show supralinear or U-shaped dose responses. The original model without the new low-dose features was also tested for consistency with LNT-shaped dose responses. Reductions of in vitro neoplastic transformation frequencies below the spontaneous level have been reported after exposure of cells to low doses of low-LET radiation. In the current study, this protective effect is explained with by-stander-induced apoptosis. An important data set that shows a low-dose detrimental bystander effect for chromosome aberrations was successfully fitted by additional terms within the cell initiation stage. It was found that this approach is equivalent to bystander-induced clonal expansion of initiated cells. This study is an important step toward a comprehensive model that contains all essential biological mechanisms that can influence dose-response curves at low doses.
\end{abstract}

\section{INTRODUCTION}

While earlier efforts to investigate the biological effects of ionizing radiation focused on high doses, low-dose effects have become the focal point in recent years (1). This research has led to the discovery of several effects that show nonlinear dose responses at low doses, putting the validity of the linear, no threshold (LNT) model into question. These low-dose phenomena include detrimental by-stander effects (2-5), protective bystander effects (6-8), genomic instability $(4,5,9)$, low-dose hyper-radiosensitivity (HRS) and induced radioresistance (IRR) (10), and adaptive responses (11-17).

The underlying biological mechanisms of these low-dose effects have been identified in part. Detrimental bystander effects are associated with damage induction in non-hit neighboring cells through gap junction-mediated intercellular communication (18) or by

(C) 2007 by Radiation Research Society. All rights of reproduction in any form reserved.

${ }^{1}$ Address for correspondence: Department of Materials Engineering and Physics, Division of Physics and Biophysics, University of Salzburg, Hellbrunnerstr. 34, A-5020 Salzburg, Austria; helmut.schoellnberger@sbg.ac.at. . 
molecules secreted into medium (19). The selective removal of non-hit damaged cells through apoptosis (20-23) and terminal differentiation together with apoptosis (7) are examples of non-genotoxic bystander-induced radioprotective mechanisms. It has also been shown that a bystander-induced increase in the radioresistance of non-hit cells is caused by an increase in DNA repair (i.e., the DNA base excision repair enzyme AP endonuclease) and cell growth/cell cycle regulation (6). IRR has been related to induced DNA repair, and the absence of such repair would be characteristic of HRS (10). The biological mechanisms mediating the adaptive response could involve DNA repair processes as well as radical scavenger induction, apoptosis and cell cycle arrest $(11,24-26)$ and have also been shown to be a bystander-mediated response (13). The original adaptive response experiments applied a challenge dose to visualize the protective effect of the adaptive dose. The protective effects found in a series of novel experiments that started with Azzam et al. (12) show the protective effect of the low dose alone through a reduction of the in vitro neoplastic transformation frequency below the spontaneous level (14-16).

The first biophysical model for detrimental bystander effects was the $B a D$ model of Brenner et al. (32). Others have presented models for bystander effects for in vitro neoplastic transformation and cancer (33-35). Models for IRR (36) and adaptive response (28, 30, 31, 36-38) have been developed. The phenomenon of HRS and IRR is reflected in the Induced Repair model (39).

The aim of the current study was to implement detrimental and apoptosis-mediated protective bystander effects into a State-Vector Model (SVM) for in vitro neoplastic transformation (40) and to test the model on several representative data sets that show supralinear $^{2}$ effects at low doses, U-shaped dose responses or LNT-shaped curves. The terms "detrimental" and "protective" as used in the current study refer to the end points analyzed here and not necessarily to carcinogenesis in humans.

\section{MATERIALS AND METHODS}

\section{The Model}

The SVM is depicted in Fig. 1. The model equations are given in Eqs. (1)-(6). Here $N_{I}(t)$ is the number of cells in state $i$ at time $t$. The rate constants $k_{i j}$ (unit of time ${ }^{-1}$ ) denote transitions from state $i$ to state $j$ (Table 1). A state vector denotes the fraction of cells in each of the states at time $t$ :

$$
\left[\frac{N_{0}(t)}{N_{T}(t)}, \frac{N_{1 s}(t)}{N_{T}(t)}, \frac{N_{1 n s}(t)}{N_{T}(t)}, \frac{N_{2}(t)}{N_{T}(t)}, \frac{N_{3}(t)}{N_{T}(t)}, \frac{N_{4}(t)}{N_{T}(t)}\right]
$$

Here $N_{T}(t)=N_{0}(t)+N_{1 s}(t)+N_{1 n s}(t)+N_{2}(t)+N_{3}(t)+N_{4}(t)$.

The model describes a very important process in the formation of in vitro neoplastic transformation and cancer: chromosome aberrations, specifically, translocations and inversions $(41,42)$. The model comprises different stages of genomic damage. State 0 cells are normal cells and divide with mitotic rate constant $k_{m}$ (cell divisions per time unit). ${ }^{3}$

\footnotetext{
${ }^{2}$ Here supralinear means having positive but decreasing slope at small doses, corresponding to a positive first derivative and negative second derivative near the origin for the dose-response curve; such behavior typically means that the actual dose-response curve at low doses lies above a linear extrapolation from a higher dose to the origin.

${ }^{3}$ The mitotic rate constant $k_{m}$ is associated with the mean cell cycle duration: a cell cycle duration of $20 \mathrm{~h}$, for example, corresponds to a mitotic rate constant $k_{m}$ of $1 / 20 \mathrm{~h}^{-1}$ or $24 / 20 \mathrm{day}^{-1}$. For some cell lines cell doubling times are reported below. While in general the doubling time may either be greater than (if some cells die or stop dividing) or equal to the cell cycle duration, for the current study it is assumed that as a first approximation the doubling time equals the cell cycle duration.
} 
Cells in State 1s contain a DSB in transcriptionally active DNA, while cells in State 1ns received a DSB in inactive DNA. Cells in State 2 contain both types of DSBs. The two pieces of DNA created by the DSBs have a certain probability to undergo a transposition, the movement of a piece of DNA to another place on the same or another chromosome (from one gene to another part of the genome) or to be misrepaired (State 3 cells). This interaction is governed by rate constant $k_{23}$ (Table 1). Cells in State 4 are initiated and are not considered to be repairable. They contain all forms of chromosomal aberrations (such as intrachromosomal paracentric inversions, interstitial deletions, pericentric inversions and interchromosomal translocations) that can be caused by two DSBs. Here, the term initiation refers to the first of two main steps toward malignant transformation of cells in vitro (42). The model equations are linear ordinary differential equations:

$$
\begin{gathered}
\frac{d N_{0}}{d t=} \begin{aligned}
&\left(k_{m}-k_{01 s}-k_{01 n s}-k_{d}\right) N_{0}+\left(k_{r s}+2 \times k_{m}\right) N_{1 s} \\
&+\left(k n_{r n s}+2 \times k_{m}\right) N_{1 n s}+2 k_{m} N_{2}
\end{aligned} \\
\frac{d N_{1 s}}{d t}=k_{01 s} N_{0}+k_{r n s} N_{2}-\left(k_{01 n s}+k_{r s}+k_{m}+k_{d}\right) N_{1 s} \\
\frac{d N_{1 n s}}{d t}=k_{01 n s} N_{0}+k_{r s} N_{2}-\left(k_{01 s}+k_{r n s}+k_{m}+k_{d}\right) N_{1 n s} \\
\frac{d N_{2}}{d t}=k_{01 n s} N_{1 s}+k_{01 s} N_{1 n s}-\left(k_{r s}+k_{r n s}+k_{23}+k_{m}+k_{d}\right) N_{2} \\
\frac{d N_{3}}{d t}=k_{23} N_{2}+\left(k_{m 3}-k_{34}-k_{d}\right) N_{3}
\end{gathered}
$$

The DSB repair pathways include a cell cycle-independent contribution and a cell cycleassociated contribution. DSBs in States $1 \mathrm{~s}$ and $1 \mathrm{~ns}$ can be repaired with rate constants $k_{r s}$ and $k_{r n s}$ (Table 1). These repair opportunities can be triggered by DSBs themselves and are assumed to occur at constant levels irrespective of the stage in the cell cycle that the cell is in. Experimental evidence supports the use of a larger rate constant for the repair in transcriptionally active DNA $\left(k_{r s}\right)$ compared to the repair in inactive DNA $\left[k_{r n s}(43,44)\right]$. At several points in the cell cycle, however, the cell enters stages in which repair is particularly important and effective. For example, repair is triggered by preparation for mitosis; this is the reason for the $\mathrm{G}_{2}$ arrest. The fraction of time a cell spends in these repair-enhanced stages depends on whether the cell is quiescent or moving through the cycle. The extent to which a population of cells is moving through the cycle therefore depends on the mitotic rate constant. When the mitotic rate is high, more of the cells would be in the pre-mitotic stages in which postreplication repair occurs. This does not mean that the rate of repair during one of these repair-enhanced stages changes with mitotic rate but rather that the probability of a given cell being in such a stage increases as the mitotic rate increases. In the SVM, DSB repair governed by the mitotic rate constant $k_{m}$ is allowed for cells in States $1 \mathrm{~s}, 1 \mathrm{~ns}$ and 2 . It is emphasized that despite its relationship to $k_{m}$, this repair does not happen during mitosis. All three repair opportunities $\left(k_{r S}\right.$ and $k_{r n s}$ and the cell cycle-associated postreplication 
repair) represent HR and non-homologous end joining (NHEJ). Cells in all stages can undergo cell killing with rate constant $k_{d}$. It is $k_{d}=k_{d b}+k_{d r} \times D R$, where $k_{d b}$ is the background rate constant of cell killing, $k_{d r}$ is the radiation-dependent rate constant of cell killing, and $D R$ is the dose rate. Figure 1 also shows a bystander-induced pathway to apoptosis for State 4 cells with rate constant $k_{a p}$ as described below.

A fraction, $F$, of the initiated cells has a growth advantage and divides with an enhanced mitotic rate constant $k_{m p}=k_{\text {mmult }} \times k_{m}$, where $k_{\text {mmult }}>1$ (L. Fleishman et al., unpublished results). In this subpopulation, intercellular communication has been disrupted, resulting in a loss of contact inhibition. The other fraction, $(1-F)$, of initiated cells divide at rate constant $k_{m}$. For the fit of one of the data sets (45), the fraction $F$ is calculated with a binomial distribution as the probability that an initiated cell is surrounded by four, five or six inactivated cells out of six surrounding cells ${ }^{4}$ (40). In the SVM, promotion is described as the above-mentioned growth advantage resulting from the loss of contact inhibition of a fraction of the initiated cells. When the model was fitted to the data on chromosome aberrations, $F=0$ was applied, because the formation of chromosome aberrations does not involve promotion. In the experiments of Miller et al. (45), who used C3H 10T $1 / 2$ cells, contact inhibition is restored when the culture is confluent. This is simulated in the model as described below.

\section{The Data}

Redpath et al. (15)—Cells of the non-tumorigenic HeLa $\times$ skin fibroblast human hybrid cell line CGL1 were irradiated with $\gamma$ rays with doses ranging from $1 \mathrm{mGy}$ to $1 \mathrm{~Gy}$ at the following dose rates: $3.3 \mathrm{mGy} / \mathrm{min}$ (for doses $\unlhd 100 \mathrm{mGy}$ ), $41.3 \mathrm{mGy} / \mathrm{min}$ (30 and $50 \mathrm{cGy}$ ) and $1.61 \mathrm{~Gy} / \mathrm{min}$ at $1 \mathrm{~Gy}$. The pooled low-dose data show a highly significant reduction in the transformation frequency per surviving cell compared to the zero dose for the delayed plating protocol (15). The data of Redpath et al. (15) were chosen because they are the most comprehensive data set to date for in vitro neoplastic transformation after $\gamma$ irradiation that shows protective effects at low doses.

Nagasawa and Little (48)-The data show a detrimental bystander effect for total chromosome aberrations in wild-type Chinese hamster ovary (CHO) and xrs-5 cells for chromosome aberrations after irradiation with $3.7 \mathrm{MeV}$ a particles at a dose rate of $9.9 \mathrm{cGy} /$ $\min$ and $112 \mathrm{keV} / \mu \mathrm{m}(48)$.

Miller et al. (45)—The neoplastic transformation frequency per surviving cell is given for acute irradiation of $\mathrm{C} 3 \mathrm{H} 10 \mathrm{~T}^{1} / 2$ cells with a particles. These data (45) were chosen because they are the most comprehensive set of data for in vitro neoplastic transformation for broadbeam irradiations. Here the data for $150 \mathrm{keV} / \mu \mathrm{m}$ a particles are used as a representative set of data for a particles among the larger data set (45). The dose rates at $150 \mathrm{keV} / \mu \mathrm{m}$ are 0.24 $\mathrm{Gy} / \mathrm{s}$ and $0.26 \mathrm{~Gy} / \mathrm{s}$ for the first and second subset, respectively (Steve Marino, personal communication).

\section{Numerical Techniques, Likelihoods and Optimization Procedures}

The model equations were solved numerically for each dose and dose rate for the different periods of the various experiments using a stiff solver ("ode15s") for ordinary differential

\footnotetext{
${ }^{4}$ When co-cultured at a ratio of 1:1, non-transformed WB-neo cells could not inhibit the growth of neoplastically transformed WB-ras and WB-neu cells. However, when seeded at a 4:1 ratio (80,000 WB-neo cells/20,000 WB-ras cells or 80,000 WB-neo cells/20,000 WB-neu cells), significant inhibition of tumor cell growth was evident (46). The growth of initiated cells can also be suppressed by surrounding normal cells (47). The fact that in the SVM at least four out of six surrounding cells must be dead to interrupt GJIC is consistent with the threshold-like behavior reported in ref. (46).
} 
equations of the Matlab@ software package. This yields the numerical values for $N_{I}(t)$. The data used to test the model show either the number of chromosome aberrations per surviving cell or the transformation frequency per surviving cell, i.e. the number of neoplastic foci (transformants per surviving cell). To fit these data, we calculate for each dose

$$
\begin{aligned}
f_{4}\left(t_{\text {end }}\right)= & {\left[N_{4}\left(t_{\text {end }}\right)\right] /\left[N_{0}\left(t_{\text {end }}\right)+N_{1 s}\left(t_{\text {end }}\right)+N_{1 n s}\left(t_{\text {end }}\right)\right.} \\
& \left.+N_{2}\left(t_{\text {end }}\right)+N_{3}\left(t_{\text {end }}\right)+N_{4}\left(t_{\text {end }}\right)\right],
\end{aligned}
$$

where $t_{\text {end }}$ is the time at the end of the experiment. For the data on chromosome aberrations, this expression needs to be multiplied by a suitable proportionality constant to reflect the fact that only a fraction of the measured chromosome aberrations will initiate a cell (36). To test the influence of the type of numerical solver on the outcome of the model fits, other available solvers of this software package that solved for non-stiff differential equations were also applied. Solutions of stiff equations can change on a time scale that is very short compared to the interval of integration, but the solution of interest changes on a much longer time scale.

A grid search optimization procedure implemented in Matlab@ was applied that allows searching the parameter space at a global level. For $n$ free parameters, the summed relative errors were calculated for an $n$-dimensional space of parameter combinations, and a minimum value was found in an $n$-dimensional matrix of relative errors. The parameter value combination that corresponded to this minimum summed relative error value was chosen as the optimal unknown parameter combination. For some model fits, however, the least-squares-based error led to better fits. Fine tuning was performed with the Nelder-Mead Simplex algorithm (49).

\section{Low-Dose Features Implemented in the Model}

Of the data sets used, four show nonlinearities at lower doses. To fit these data, biological mechanisms that may lead to these nonlinearities were included in the model.

Apoptosis-mediated protective bystander effects-Experimental evidence indicates that protective apoptosis-mediated [termed PAM by Scott et al. (30)] effects can be induced by low-dose radiation in non-hit by-stander cells, whereby neoplastically transformed mammalian cells are eliminated by their non-transformed neighboring cells through intercellular, TGF- $\beta$-mediated, induction of apoptosis (23). For brevity, the term "PAM process" is referred to here as PAM. Two main pathways for the intercellular signaling between non-transformed and transformed fibroblasts have been identified: the hypochlorous acid/hydroxyl radical pathway and the NO/peroxynitrite pathway $(20,21,50)$. These mechanisms represent protective bystander effects, which were modeled in a simplified biophysical way in the current study. An additional pathway was added that accounts for bystander-induced apoptosis that allows for the removal of initiated cells (Fig. 1). The parameter $k_{a p}$ governs the rate of commitment of initiated cells in State 4 to bystander-induced apoptosis. The unit for $k_{a p}$ is time ${ }^{-1}$. Induction of bystander-induced apoptosis in cells with severe and persistent damage is biologically feasible $(20,21)$. The following assumptions are made with respect to the occurrence of this by-stander effect.

1. PAM is effective at low doses only_no effect at doses $>200 \mathrm{mGy}$.

2. PAM can eliminate cells in State 4 (initiated).

3. $k_{a p}=0$ at $D=0$.

4. PAM is activated by $1 \mathrm{mGy}$ low-LET radiation $(12,15,16)$ but becomes effective only after exposure $(23,31)$. 
5. PAM is activated for various times after irradiation.

Detrimental bystander effects-Based on experimental studies, there are different possibilities regarding how radiation can damage non-hit neighboring cells (9). In the SVM, a dose- and dose-rate-dependent term, $k_{01 r_{-} b y} \times D R \times \exp \left(-\lambda_{2 b y} \times D\right)$, was added to rate constant $k_{01 \text { ns }}$ [but not to $k_{01 s}$, because in the SVM $k_{01 s r}=0(40)$ ]. Here $D$ is the dose. This reflects the possibility that for long exposure times radiation may initiate cells during exposure by non-targeted effects. Detrimental bystander effects may also occur after exposure, which can lead to initiation of non-hit cells. This was accounted for by including $k_{01 b_{-} b y} \times \exp \left(-\lambda_{1 b y} \times D\right)$ with the rate constants $k_{01 s}$ and $k_{01 n s}$. Another possibility to account for by-stander effects is to multiply the mitotic rate constants $k_{m}$ by [ $1+k_{m_{-} b y} \times$ $\left.\exp \left(-\lambda_{3 b y} \times D\right)\right]$. This accounts for the findings that tissue responses may promote preexisting initiated cells (9). In the present study, these approaches were tried out one at a time so that two free parameters were always estimated by fitting the whole data set for either CHO or xrs-5 cells (48).

\section{RESULTS}

For those data sets that show nonlinear effects at low doses, the following procedure was applied. At first, those free parameters not associated with the low-dose nonlinearities were estimated by fitting the model, without the low-dose features, to the control and high-dose data points. The model with low-dose features was then fitted to the whole data set, with the other parameter values as fixed input. Results of model fits performed with numerical solvers other than "ode15s" were very close to those presented below.

\section{Fit of the Data of Redpath et al}

CGL1 cells were irradiated when they were subconfluent. In one set of experiments, Redpath et al. (15) applied a 1-day holding period after which the cells were plated at low cell density. In the other set of experiments, the cells were plated immediately after irradiation. During irradiation, the mean doubling time was approximately $20 \mathrm{~h}\left[(51) ; k_{m}=\right.$ $1.2 /$ day]. For the 1-day postirradiation holding period, it can be assumed that the mitotic rate constant would be about the same as during irradiation because the induced $\mathrm{G}_{2}$ delay would be minimal after the low radiation doses up to $1 \mathrm{~Gy}$ applied in the experiments. After the holding period, the cells were seeded at low cell density, and after an initial delay of a few hours (which is not simulated here due to lack of precise information), the cells divided approximately every $20 \mathrm{~h}\left(k_{m}=1.2 /\right.$ day $)$. After approximately 10 days, the cultures became confluent (51). During confluence, the net clonal expansion rate, $k_{m}-k_{d b}$, was calculated to be approximately $0.026 /$ day. This value is based on an analysis of the growth curve given in Fig. 1 of Mendonca et al. (51), who used cells of the same cell line. Because obtaining independent values for $k_{m}$ and $k_{d}$ is not possible, $k_{m}-k_{d b}=0.026 /$ day is used during plateau phase, with $k_{d b}=0$. Survival data revealed that up to $1 \mathrm{~Gy}$, no significant cell killing occurred. Therefore, $k_{d r}=0$. CGL1 cells do not respond to contact inhibition signals and continue to divide (52). Therefore, $F$, the fraction of initiated cells that are not contact

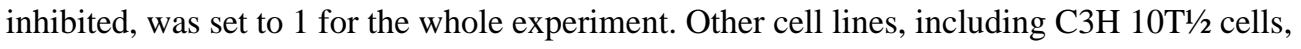
show contact inhibition when they enter plateau phase. Because no fraction of the CGL1 cells cycles at an elevated mitotic rate, $k_{\text {mmult }}$ was set to 1 .

The model was fitted to the data in two steps. First, the model with $k_{a p}=0$ was fitted to a set of $2 \times 4$ data points $(0,0.3,0.5$ and $1 \mathrm{~Gy})$ for immediate and delayed plating simultaneously [fit1; the fit itself is shown in ref. (53)]. At higher doses, more lesions are produced that are difficult to repair. Since these persist for relatively long times, this allows the possibility of their interaction to form a new lesion that may be even more difficult (slower) to repair (54). 
Therefore, an exponential damping factor $\left(e^{-\lambda}\right.$ decr $\left.D\right)$ was applied to $k_{I S}, k_{I n S}$ and the cell cycle-associated repair. A good fit of the data was achieved when it was assumed that prior to irradiation a fraction $f_{4}(0)$ [refer to Eq. (7)] is already initiated by endogenous influences. With this background transformation frequency, the initial state vector applied in the model fits becomes $\left[1-f_{4}(0), 0,0,0,0, f_{4}(0)\right]$. The values allowed for $f_{4}(0)$ ranged from $10^{-5}$ to $10^{-4}$. The best estimates for the five free parameters are given in Table 2 (fit1).

With the best estimated values from fit 1 as fixed input, a forward simulation with $k_{a p}=0$ of the whole data set for immediate plating was performed (Fig. 2A, "direct contribution"). Here $t_{c o n}=\mathrm{ET}+10$ days and $t_{\text {end }}=\mathrm{ET}+25$ days, where ET is the exposure time for each dose. In addition, fit 2 was performed with $k_{a p}$ as free parameter to investigate the protective effects in this data set compared to the data for delayed plating (Fig. 2A, "total contribution"). In fit $3, t_{\text {ap_off }}$, the time after the start of irradiation when PAM is switched off was also treated as a free parameter. The model was then fitted to the whole data set for delayed plating (with $t_{c o n}=\mathrm{ET}+11$ days, $t_{\text {end }}=\mathrm{ET}+26$ days) using one $\left(k_{a p}\right.$, fit 4 , Fig. $\left.2 \mathrm{~B}\right)$ or two free parameters $\left(k_{a p}, t_{a p_{-} o f f}\right.$, fit5). In fit2 and fit4, PAM was switched off when the cells reached plateau phase. In all these fits, the best estimated values from fit 1 were used as fixed input.

\section{Fit of the Data of Nagasawa and Little}

The surviving fractions of $\mathrm{CHO}$ cells after a-particle irradiation (2) were used to estimate $k_{d r}(2.11 / \mathrm{Gy})$. This value was also applied in the fit of the data for xrs-5 cells. The mean doubling times for $\mathrm{CHO}$ and xrs-5 cells are $12\left(k_{m}=2 /\right.$ day $)$ and $13 \mathrm{~h}\left(k_{m}=1.85 /\right.$ day $)$, respectively (48). Chromosome aberrations were analyzed $19 \mathrm{~h}$ after the irradiation (48), i.e. $t_{\text {end }}=19 \mathrm{~h}$. For the fit of the data for CHO cells, the SVM without bystander features was first fitted to the control and high-dose data points at 1 and $2 \mathrm{~Gy}$ (fit6). Here $k_{01 b_{-} b y}=0$ was applied. This yields the model-predicted chromosomal aberration frequency from direct effects (Fig. 3A). The initial state vector applied was $[1,0,0,0,0,0]$. The full data set was then fitted with the best estimates from fit6 as fixed inputs (fit7, Table 3). In fit7, the model adapted with bystander features was applied. This yields the model-predicted total chromosomal aberration frequency (Fig. 3A). The data for xrs-5 cells were fitted analogously (fit8 and fit9, Table 3, Fig. 3B). The fact that xrs-5 cells are deficient in NHEJ was accounted for by applying a reduction factor, $\lambda_{r e d}$, to $k_{r s}, k_{r n s}$ and the cell cycleassociated repair. In all these fits, $F=0$.

\section{Fit of the Data of Miller et al}

The data show essentially a linear dose-response relationship (Fig. 4). Therefore, the SVM without any special low-dose features was fitted to these data. The mean cell cycle duration of the $\mathrm{C} 3 \mathrm{H} 10 \mathrm{~T}^{1} / 2$ cells used by this group of researchers is approximately $20 \mathrm{~h}(55)$.

Therefore, $k_{m}=1.2 /$ day. The surviving fractions [Table II in ref. (45)] were fitted with the term $e^{-k_{d r} D}$ to yield $k_{d r}=2.13 / \mathrm{Gy}$ (fit not shown). For the data of Miller et al., a radiationinduced loss of contact inhibition of initiated cells is simulated. C3H $10 \mathrm{~T}^{1 / 2} 2$ cells surrounding an initiated cell get hit by a particles and die. Consequently, the initiated cell receives fewer growth-inhibitory signals and starts to divide more rapidly. When the dead cells are replaced by viable cells (either by division of surrounding viable cells or by division of the initiated cells themselves), contact inhibition can be restored. This situation usually occurs when the plate is full, i.e. when the cells enter plateau phase (become confluent). This is modeled by a linear decrease in the initial fraction of dead cells (L. Fleishman et al., unpublished results). The fraction will be 0 when exponential growth ceases and plateau phase starts. A standard tissue culture flask holds approximately $10^{6}$ cells when it is full. The time when cells reach confluence (i.e. end of exponential growth), $t_{\text {con }}$, can then be calculated using the number of viable cells per dish (45) and $k_{m}=1.2 /$ day. We 
get $t_{\text {con }}=6.75$ days. The model equations were solved from $t=0$ until the end of the experiment at $t=t_{\text {end }}=42$ days. In the fit of these data, it was assumed that prior to irradiation all cells were undamaged (i.e. in state 0 ), so the initial state vector applied was [1, $0,0,0,0,0]$. Figure 4 shows the model fit to the data. The two subsets of data for $150 \mathrm{keV/}$ $\mu \mathrm{m}$ a-particle exposure have been fitted jointly. Initial fits revealed that the best estimated value for $k_{\text {mmult }}$ was very close to 1 . Therefore, $k_{\text {mmult }}=1$ was used as a fixed input in the model fit. The best estimates for the three free parameters are given in Table 3 (fit10). Here the approximation $k_{01 s r}=0$ was applied..$^{5}$

\section{DISCUSSION}

In the current study, a biologically based multistage model for chromosome aberrations and in vitro neoplastic transformation has been tested on various data sets from cell culture studies. While the limitations of cell culture studies have been stated (56), one advantage is that they allow investigations of biological mechanisms that are relevant for human exposure at low doses. The current work focuses on two important low-dose effects that have been discovered in recent years: detrimental bystander effects (2-5) and protective apoptosis-mediated bystander effects $(7,20-23,50)$. Biological mechanisms that had earlier been associated with these effects were implemented into the model.

The SVM is biologically motivated. Within the initiation submodel, it describes an important process in the formation of in vitro neoplastic transformation and cancer: chromosome aberrations, specifically, translocations and inversions (41). The repair pathways represent DSB repair in quiescent cells $\left(k_{r S}\right.$ and $k_{r n s}$, Table 1). Despite its relationship to $k_{m}$, cell cycle-associated repair does not happen during mitosis but represents a postreplication repair pathway. The concept of unrepairable initiated cells is firmly established (57). For the simulation of in vitro neoplastic transformation, the SVM then describes the clonal expansion of a fraction $F$ of the initiated cells that have a decreased GJIC (58). Mutagenic genotoxic carcinogens such as ionizing radiation do not inhibit GJIC or induce cell proliferation (58). In the SVM, the disruption of GJIC stems from dead cells surrounding initiated cells (40). For the fit of the data of Miller et al. (45), the fraction of initiated cells with increased mitotic rate is calculated as explained above. Contact inhibition can be restored when the plate is full and the cells become confluent. This re-establishment of contact inhibition is included in the model for the fit of the Miller data: $F=0$ at the end of exponential growth. It is also plausible to use $F=0$ for chromosome aberrations because the formation of chromosome aberrations does not involve promotion. For the fit of the data of Redpath et al. (15), $F=1$ is used because the CGL1 cells show a lack of density-dependent inhibition of division (52).

\section{Data of Redpath et al}

At doses $<300 \mathrm{mGy}$, the data sets of Redpath et al. (15) show a reduced transformation frequency compared to the zero dose (Fig. 2). The reduction was greater for delayed plating. This groundbreaking observation of the anti-transformation effect of low doses is a relatively recent discovery (12). In the current study, the data of Redpath et al. (15) were successfully fitted with a model that allows for bystander-induced apoptosis at low doses. Earlier, the data of Azzam et al. (12) were fitted applying the concept of induced HR as

\footnotetext{
${ }^{5}$ Estimations for $k 01 s r$ based on biophysical considerations have been provided for an earlier version of the SVM, and a value of $1.4 \times$ $10^{-4}$ /Gy was reported for a particles (40). Here, a model fit of the data of Miller et al. (45) has been performed analogous to fit 10 but with $k_{01} s r$ as free parameter in the local fit applying $k_{01} s r=0$ as starting value. The latter is consistent with the use of $k_{01} s r=0$ in the global fit. This led to the following best estimated values: $k_{01} s b=12,860.53 / \mathrm{day}, k_{01} s r=1.54 \times 10^{-6} / \mathrm{Gy}, k_{01} \mathrm{nsb}=149.95 / \mathrm{day}$, $k_{01} n s r=4941.97 / \mathrm{Gy}$ with least-squares-based error $=1.198 \times 10^{-7}$. Because this fit is not significantly better than fit 10 and the value of $k_{01} s r$ is very small, it is justified to use the approximation $k_{01} s r=0$.
} 
proposed by Azzam et al. $(11,12)$ and an up-regulation of the radical scavenging capacity (28). Pant et al. (27) showed that up-regulation of GSH levels is not involved in the reported suppression of transformation frequency in the currently used data of Redpath et al. (15). They also showed that up-regulation of DNA repair may be involved at 5 cGy but not at 0.5 cGy. Pant et al. (27) also point out that at doses of $0.1 \mathrm{cGy}$ and less, where a significant number of cells will not even experience an ionizing event, there is still suppression of the transformation frequency $(12,15,16)$ and that under such circumstances bystander effects may become more important. Redpath et al. (29) showed that the killing of the transformation-sensitive $\mathrm{G}_{2} / \mathrm{M}$-phase subpopulation could account at least in part for the observed reduction of the transformation frequency at low doses to levels below that of the spontaneous frequency. However, since the $\mathrm{C} 3 \mathrm{H} 10 \mathrm{~T}^{1} / 2$ cells used by Azzam et al. (12) were confluent during irradiation (i.e. remaining in $\mathrm{G}_{0} / \mathrm{G}_{1}$ ), any selective $\mathrm{G}_{2} / \mathrm{M}$-phase killing effect would not apply to these data. It has recently been proposed that the protective effects seen in the data of Redpath et al. (15) might be due to bystander-induced apoptosis (23).

In the current study, PAM is allowed to eliminate initiated cells (Fig. 1) already present before the exposure and newly induced initiated cells that are produced during exposure and the growth period $(30,31)$. In the model fits, PAM is active only at doses $\_200 \mathrm{mGy}$. This is based on the data for delayed plating (15), which show that the transition between protective and detrimental effects occurs between 100 and $300 \mathrm{mGy}$ (Fig. 4B). The model also correctly describes the observation that even at $1 \mathrm{mGy}$ the full protective effect occurs (Fig. 2 insets). The rate constant associated with PAM, $k_{a p}$, is currently assumed to not be dependent on dose rate, in accordance with the findings of Vral et al. (59) and Fujikawa et al. (60). Dose-rate dependence for induction of apoptosis has been found, however, at 0.15 $\mathrm{cGy} / \mathrm{min}$ but not at $0.29 \mathrm{cGy} / \mathrm{min}$ (61). Redpath et al. (15) used $0.33 \mathrm{cGy} / \mathrm{min}$. Therefore, the data of Boreham et al. (61) confirm that the model approach is correct for the data of Redpath et al. (15).

The fact that five free parameters were necessary for fit 1 can be considered as a weakness of the SVM approach. It is emphasized, however, that instead of making $f_{4}(0)$ a free parameter, a suitable value for it could also be taken from the data themselves (the mean of the two control values) as fixed input for the initial state vector. That would reduce the number of free parameters by one. All other fits had fewer free parameters (refer to Tables 2 and 3). When fitting the data with PAM, two different approaches were applied. At first, $k_{a p}$ was the only free parameter with $t_{a p \_o f f} \equiv 11$ days + ET. This yielded $k_{a p}=0.024 /$ day and $k_{a p}=$ $0.054 /$ day in fit 2 and fit 4 , respectively. When both $k_{a p}$ and $t_{a p \_o f f}$ were treated as free parameters, smaller values for $k_{a p}$ were found but with longer times of PAM induction (Table 2), while the quality of the fits was slightly improved. This shows that $k_{a p}$ and $t_{a p \_o f f}$ are inversely related to each other, which is biologically feasible. A longer period of PAM induction compensates for a smaller rate of induction and vice versa. The best estimated value for $k_{a p}$ in fit4 is approximately twice as large as $k_{a p}$ in fit 2 . An analogous result is found in fit 5 compared to fit 3 with similar values for $t_{a p \_o f f}$. The initial drop in transformation frequency as the dose increased from 0 to $1 \mathrm{mGy}$ in fit 4 is also approximately twice as large as in fit2 (see insets in Fig. 2A and B). All of this reflects the fact that the data for delayed plating show a stronger protective effect compared to the data for immediate plating.

To investigate whether the model with two free parameters is superior to the model with only one free parameter, an $F$ test was applied to the variances $\sigma^{2}$ of fit4 to fit5 (Table 2). It is 


$$
\sigma^{2}=\sum_{i=1}^{9}\left[\frac{\operatorname{TFSC}(i)-f_{4}\left(t_{\mathrm{end}}, i\right)}{\operatorname{TFSC}(i)}\right]^{2} .
$$

Here TFSC $(i)$ is the $i$ th measured transformation frequency per surviving cell in the data of Redpath et al. (15) and $f_{4}\left(t_{\text {end }}, i\right)$ is the ratio from Eq. (7) for the $i$ th dose. One then calculates $F=\sigma_{1}^{2} / \sigma_{2}^{2}$, where $\sigma_{i}^{2}$ is the variance of the $i$ th model fit. The calculated $F$ value is then compared to the corresponding entry on a table of $F$-test critical values at a significance level of $a=0.05$ for $m$ and $n$ degrees of freedom $(d f)$ and $d f=$ number of data points number of free parameters -1 . For fit $4, m=7$ and $\sigma^{2}=0.074$. For fit5, $n=6$ and $\sigma^{2}=0.072$ (Table 2). One gets $F=1.06$, which is smaller than the tabulated value of 4.21 at $a=0.05$ for $m=7$ and $n=6$. Therefore, it can be said that with a probability of 0.95 the two variances are not significantly different. Fit5 is not better than fit 4 at the 5\% significance level. An analogous result was found for fit 3 with respect to fit 2 . This means that the data at hand cannot be used to prove that the model with two free parameters is better than the model with one free parameter. More data points would be necessary to lead to smaller tabulated $F$ test values. That would better enable to distinguish different model fits statistically.

The relatively long time of approximately 24 days for PAM induction (fit5) is reflected in the scientific literature. Jamali and Trott (62) reported a 2-week induction of apoptosis after a $1-G y \times$ irradiation at $0.5 \mathrm{~Gy} / \mathrm{min}$. A sensitivity analysis was performed with respect to parameter $t_{a p \_o f f}$. It was found that the model predictions are quite sensitive to the value of this free parameter. This was investigated with the data for delayed plating at a dose of 0.01 Gy and with $k_{a p} \equiv 0.025 /$ day (fit5). The difference between the model-predicted values for transformation frequency at control and $0.01 \mathrm{~Gy}$ was assigned a $\Delta$ value of $100 \%$. The earlier PAM was switched off, the smaller the $\Delta$ values, which means less protection and therefore a shallower $\mathrm{U}$ shape. At $t_{\text {ap_off }}=5,10$ and 15 days, the $\Delta$ values were $25.2 \%$, $47.9 \%$ and $69.8 \%$, respectively.

The values for $k_{a p}$ can be analyzed further in terms of the number of State 4 cells eliminated. A forward simulation has been performed for $D=0.1 \mathrm{~Gy}$ with the best estimate from fit 4 . The simulation yields $N_{4}(t=26+$ ET days $)=13.6$; i.e., the simulation predicts that after an exposure to $0.1 \mathrm{~Gy}$, there are approximately 14 initiated cells at the end of the growth period. When $k_{a p}=0$ is used in the same forward simulation, we get $N_{4}(t=26+$ ET days $)=$ 23.9. PAM therefore eliminates about 10 initiated cells, a rather small number. The protective effect from $0.1 \mathrm{~Gy} \gamma$ radiation at low dose rate can therefore be explained by killing only 10 initiated cells that are destined to become neoplastically transformed. Similar figures hold for the other doses $₫ 0.1 \mathrm{~Gy}$. Scott et al. (30) stated that since the observed spontaneous transformation frequency, $T_{0}$, is of the order of $10^{-4}$ to $10^{-5}$ for most in vitro studies of neoplastic transformation, selectively killing all $T_{0}$ cells would still lead to a cell surviving fraction $>0.999$. This is in full accordance to the findings reported here. It is emphasized that the small number of 10 cells reflects the fact that in this computer simulation the initial state vector was not multiplied by the mean number of viable cells that were seeded into a flask after irradiation. For delayed plating and $0.1 \mathrm{~Gy}$, that number is 3640 [derived from Table 1B in Redpath et al. (15)]. When the initial state vector is multiplied by this number, the difference in $N_{4}(26+$ ET) with and without PAM becomes accordingly larger but is still orders of magnitudes smaller than $N_{0}\left(t_{\text {end }}\right)+N_{1 \mathrm{~s}}\left(t_{\text {end }}\right)+\ldots+$ $N_{4}\left(t_{\text {end }}\right)$ with $t_{\text {end }}=26+$ ET days. A multiplication of the initial state vector with the dosedependent mean number of viable cells seeded is not necessary because this constant cancels out upon calculation of $f_{4}(26+\mathrm{ET})$ [refer to Eq. (7)]. 
In the current study, we have not tried to estimate the onset of PAM after the end of exposure. This has been addressed recently (53). While cell cycle effects currently are not included in the SVM, the selective bystander-induced elimination of initiated cells through the PAM mechanism bears similarities to the proposed killing of the transformationsensitive $\mathrm{G}_{2} / \mathrm{M}$-phase subpopulation that could explain some of the protective effects (29). Like $\mathrm{G}_{2} / \mathrm{M}$ cells, initiated cells represent a hypersensitive subfraction that is prone to neoplastic transformation.

While adaptive responses are always consequences of a single adapting dose, the new data sets of Azzam et al. (12), Redpath and Antoniono (14), Redpath et al. (15, 16), and Ko et al. (17) represent a novel approach to visualize the protective effect of low doses compared to the original experimental approach for demonstrating an adaptive response. The latter applied a second dose to show the protective effect of the adapting dose.

PAM should not be confused with apoptosis induced in hit cells. The latter is currently not explicitly included in the SVM. It can, however, be assigned to the background rate constant of cell killing, $k_{d b}$. PAM operates at low doses of low-LET radiation, while apoptosis in hit cells may occur at both low and high doses as well as after exposure to high-LET radiation (31). We speculate that PAM may be the process induced in an adaptive response experiment by Cregan et al. (24), where an adapting dose induced increased apoptosis after a larger dose in nondividing lymphocytes. This would be consistent with the idea that protection is greater when PAM continues for many days, a situation more likely in nondividing cells and not seen in lymphocytes stimulated to divide.

\section{Data of Nagasawa and Little}

The model with detrimental bystander effects was fitted successfully to the chromosomal aberration data of Nagasawa and Little (48). It was found that only a limited number of studies dealt with this end point with respect to an adverse bystander effect (63). In the study of Ponnaiya et al. (63), for example, the authors applied only three different doses, while Nagasawa and Little (48) used 14 doses in addition to the control. More recent data from the same group are available $(64,65)$, but they provide fewer data points than the 2002 data set.

The sub-models describing bystander-induced initiation that occurs after exposure [i.e. $\left.k_{01 \_b y} \times \exp \left(-\lambda_{1 b y} \times D\right)\right]$ and bystander-induced promotion of initiated cells can fit the data equally well. The dose-rate-dependent bystander model $\left[k_{01 r_{-} b y} \times D R \times \exp \left(-\lambda_{2 b y} \times D\right)\right]$ did not lead to a satisfactory description of the supralinearities visible in the data for $\mathrm{CHO}$ and xrs- 5 cells. This reflects the fact that this term is unequal to zero only during irradiation. At the low doses where the bystander effects occur, irradiation times are typically less than 1 $\mathrm{s}$. Therefore, even very high values for $k_{01 r_{-} b y}$ cannot produce a significant deviation from the model without bystander effects (not shown). Our model analyses indicate that the bystander effects associated with the data of Nagasawa and Little (48) seem to be induced predominantly postirradiation. This can be expected based on the fact that for this data set the exposure times are too short for bystander effects to cause initiation during exposure.

The fact that xrs-5 cells are deficient in NHEJ was accounted for by applying a reduction factor to $k_{T S}, k_{r n s}$ and the cell cycle-associated repair because it can be assumed that all three repair possibilities contain contributions from NHEJ (fit8, Table 3). A twofold reduction was found in fit8. A sixfold repair deficiency of xrs-5 cells compared with $\mathrm{CH}-\mathrm{K} 1$ cells was measured (66). Figure 2B shows the best fit of the full data set for xrs-5 cells (fit9).

Here a model for detrimental bystander effects for broad-beam irradiation has been presented. It is useful to compare this approach to the $B \mathrm{a} D$ model for broad-beam a-particle radiation (32). According to the $B \mathrm{a} D$ model, the predicted frequency of transformants per 
surviving cell is $v_{q}\langle\Lambda\rangle+\sigma\left[1-e^{-k}\left\langle{ }_{N}\right\rangle\right] e^{-q}\left\langle{ }_{N}\right\rangle$, where $v$ is the slope of the linear doseresponse relationship, $q$ is the probability of surviving a single a-particle traversal, $\langle N\rangle$ is the mean number of Poisson-distributed a-particle nuclear traversals, and $\sigma$ is the fraction of cells that are hypersensitive to transformation by the bystander signal. The number of unirradiated neighbor cells that receive a bystander signal from hit cells is denoted as $k(32)$. The probability that at least one of the $k$ cells is hit is $[1-\exp (-k \times\langle N\rangle)]$. The direct term in the $B \mathrm{a} D$ model, $v q\langle\Lambda\rangle$, is equivalent to $\mathrm{a} D$ (32). We therefore get a transformation frequency per surviving cell of $\alpha D+\sigma\left[1-e^{-\delta D}\right] e^{-\beta D}$. Here $\beta \equiv \alpha / \nu,\langle N\rangle=\gamma D$, and $\delta \equiv k \gamma$ (67). While the SVM does not contain an explicit signaling term, the bystander term applied in the model fit of the data of Nagasawa and Little (48), $k_{01 b_{-} b y} \times \exp \left(-\lambda_{1 b y} \times D\right)$, decreases exponentially with increasing dose. This is analogous to the $B a D$ model.

\section{Data of Miller et al}

The SVM without nonlinear low-dose features was fitted successfully to the in vitro data of Miller et al. (45). Relatively large values were obtained for the free parameters in fit10 (Table 3) when compared to the best estimates from the other fits. This has to do with the different irradiation procedures used in the experiments of Miller et al., where the narrow radiation beam was moved over the dishes and each single cell was irradiated for only a short time [at $0.1 \mathrm{~Gy}$, for example, ET =0.4 $\mathrm{s}$ for the data of Miller et al. (45) while ET = $30.30 \mathrm{~min}$ for the data of Redpath et al. (15)]. This leads to high dose rates (refer to the Materials and Methods section) that cannot, however, fully compensate for the very short exposure times within the model fits. In the optimization process, the short exposure times are compensated for by larger best estimated values to achieve the best possible fits. In the experiments performed by Nagasawa and Little (48) and Redpath et al. (15), all the cells were irradiated simultaneously and the exposure times were accordingly longer.

Similar to the SVM, the NEOTRANS model $(30,31,68)$ consists of a system of coupled ordinary differential equations that describe the formation of in vitro neoplastic transformation. It contains different stages of genomic instability, repair and misrepair and treats hypersensitive and resistant cells separately. The NEOTRANS model has been applied to data for neoplastic transformation (30, 31, 68-70) and mutations (70) using the closedform solutions for hypersensitive cells (69) or approximate closed-form solutions for low doses $(30,31,70)$ and high dose rates (68). In the current study the numerical solution of the full model [Eqs. (1) to (6)] is applied.

Mill et al. (56) performed a collaborative study among six European laboratories using $\mathrm{C} 3 \mathrm{H}$ $10 \mathrm{~T}^{1} / 2$ cells that were irradiated with $\mathrm{X}$ rays from $0.25 \mathrm{~Gy}$ to $5 \mathrm{~Gy}$ at $2 \mathrm{~Gy} / \mathrm{min}$. They concluded that the results clearly support a linear dose-response relationship for cell transformation in vitro with no evidence for a threshold dose (56). It is emphasized that the findings of Mill et al. (56) are not in contradiction to the data of Redpath et al. (15), Azzam et al. (12) and other studies from Dr. Redpath's laboratory that show protective effects at low doses. The reasons for this are as follows: Mill et al. (56) used a high dose rate, while the protective effects observed by Azzam et al. (12) and Redpath et al. (15) were seen with low dose rates of a few $\mathrm{mGy} / \mathrm{min}$. In addition, the data of Redpath et al. (15) show the transition from protection and detriment between 100 and $300 \mathrm{mGy}$. The lowest dose applied by Mill et al. (56) was $250 \mathrm{mGy}$. It is even more interesting to compare the findings of Mill et al. (56) to those of Redpath et al. (16) and Ko et al. (17), who also used X rays delivered at high dose rates. Redpath et al. (16) found the transition from protection to detriment between 40 and $180 \mathrm{mGy}$, and Ko et al. (17) found this transition between 10.8 mGy and $108 \mathrm{mGy}$. All of these doses are much smaller than the lowest dose applied by 
Mill et al. (56). It is therefore obvious that no protective effects can be expected in the study of Mill et al. (56).

In an earlier study (28), it was explained in more detail that the data of Azzam et al. (12) do not contradict the results of many other cell culture studies that did not show any thresholds or protective effects at low doses. This is because of differences in dose rates, in the level of the spontaneous transformation frequencies, and in the experimental protocols, such as delayed plating (28). Besides the current study, the SVM has been used before to successfully explain other low-dose data $(28,36)$.

Protective and detrimental bystander effects and genomic instability have predominantly been examined in vitro. Several researchers have speculated about the importance of these effects for low-dose exposure of humans. We emphasize that the use of reconstructed, normal human three-dimensional tissue systems (71) and explant techniques that allow irradiation of explant outgrowth under in vivo-like conditions (7) are leading the way to future experimental low-dose risk analyses. Biomathematical models should be tested on such data.

\section{CONCLUSIONS}

1. Two new models for detrimental and protective bystander effects were presented and successfully fitted to representative data sets.

2. A protective apoptosis-mediated bystander effect could be responsible at least in part for protective effects of low doses of $\gamma$ radiation.

3. It was found that the magnitude of the protective effect is strongly dependent on the duration of PAM.

4. New experiments are needed that investigate the potential of low doses $(<200$ $\mathrm{mGy}$ ) of low-LET radiation to induce apoptosis. The requested studies should investigate the time dependence of induction of apoptosis for at least 3 to 4 weeks after exposure.

5. The importance of adaptive responses with respect to a reduction of the neoplastic transformation frequency below the spontaneous level at low doses is emphasized.

6. The approach chosen to fit the data of Nagasawa and Little (48) is equivalent to bystander-induced promotion of initiated cells.

7. The work presented here is an important step toward a comprehensive model that contains all essential biological mechanisms that can influence dose-responses at low doses of ionizing radiation.

\section{Acknowledgments}

\footnotetext{
The authors wish to thank Mr. Steve Marino and Dr. Richard C. Miller (both at Columbia University) for their help in providing irradiation times and related fruitful discussions. We also thank Dr. Stefan Kopecky, Institute for Reference Materials and Measurements, Dr. Peter Eckl, University of Salzburg, Dr. Georg Bauer, University of Freiburg, and Dr. Hatsumi Nagasawa, Colorado State University, for fruitful discussions. We are grateful to the reviewers for their valuable criticism. This work was supported by the RISC-RAD Project (EC Contract Number FI6R-CT-2003-508842), by a Marie Curie European Reintegration Grant within the 6th European Community Framework Program (EC Contract No MERG-CT-2004-006610), by the Austrian Science Fund FWF (project P18055-N02), by the Office of Science (BER), U.S. Department of Energy, Grant Numbers DE-FG02-03ER63673, DE-FG02-03ER63648, DE-FG02-05ER64083 and Atomic Energy of Canada Limited.
} 


\section{REFERENCES}

1. NCRP. Evaluation of the Linear-Nonthreshold Dose-Response Model for Ionizing Radiation. National Council on Radiation Protection and Measurements; Bethesda, MD: 2001. Report No. 136

2. Nagasawa H, Little JB. Unexpected sensitivity to the induction of mutations by very low doses of alpha-particle radiation: Evidence for a bystander effect. Radiat. Res. 1999; 152:552-557. [PubMed: 10521933]

3. Sawant SG, Randers-Pehrson G, Geard CR, Brenner DJ, Hall EJ. The bystander effect in radiation oncogenesis. I. Transformation in $\mathrm{C} 3 \mathrm{H} 10 \mathrm{~T}^{1 / 2} / 2$ cells in vitro can be initiated in the unirradiated neighbors of irradiated cells. Radiat. Res. 2001; 155:397-401. [PubMed: 11182789]

4. Morgan WF. Non-targeted and delayed effects of exposure to ionizing radiation: I. Radiationinduced genomic instability and bystander effects in vitro. Radiat. Res. 2003; 159:567-580. [PubMed: 12710868]

5. Morgan WF. Non-targeted and delayed effects of exposure to ionizing radiation: II. Radiationinduced genomic instability and bystander effects in vivo, clastogenic factors and transgenerational effects. Radiat. Res. 2003; 159:581-596. [PubMed: 12710869]

6. Iyer R, Lehnert BE. Low dose, low-LET ionizing radiation-induced radioadaptation and associated early responses in unirradiated cells. Mutat. Res. 2002; 503:1-9. [PubMed: 12052498]

7. Belyakov OV, Folkard M, Mothersill C, Prise KM, Michael BD. Bystander-induced apoptosis and premature differentiation in primary urothelial explants after charged particle microbeam irradiation. Radiat. Prot. Dosimetry. 2002; 99:249-251. [PubMed: 12194297]

8. Barcellos-Hoff MH, Brooks AL. Extracellular signaling through the microenvironment: A hypothesis relating carcinogenesis, bystander effects, and genomic instability. Radiat. Res. 2001; 156:618-627. [PubMed: 11604083]

9. Lorimore SA, Wright EG. Radiation-induced genomic instability and bystander effects: related inflammatory-type responses to radiation-induced stress and injury? A review. Int. J. Radiat. Biol. 2003; 79:15-25. [PubMed: 12556327]

10. Joiner MC, Marples B, Lambin P, Short SC, Turesson I. Low-dose hypersensitivity: current status and possible mechanisms. Int. J. Radiat. Oncol. Biol. Phys. 2001; 49:379-389. [PubMed: 11173131]

11. Azzam EI, Raaphorst GP, Mitchel RE. Radiation-induced adaptive response for protection against micronucleus formation and neoplastic transformation in $\mathrm{C} 3 \mathrm{H} 10 \mathrm{~T}^{1} \frac{2}{2}$ mouse embryo cells. Radiat. Res. 1994; 138(Suppl.):S28-S31. [PubMed: 8146320]

12. Azzam EI, de Toledo SM, Raaphorst GP, Mitchel REJ. Low-dose ionizing radiation decreases the frequency of neoplastic transformation to a level below the spontaneous rate in C3H 10T $1 / 2$ cells. Radiat. Res. 1996; 146:369-373. [PubMed: 8927708]

13. Broome EJ, Brown DL, Mitchel REJ. Dose responses for adaption to low doses of ${ }^{60}$ Co gamma rays and ${ }^{3} \mathrm{H}$ beta particles in normal human fibroblasts. Radiat. Res. 2002; 158:181-186. [PubMed: 12105988]

14. Redpath LJ, Antoniono RJ. Induction of an adaptive response against spontaneous neoplastic transformation in vitro by low-dose gamma radiation. Radiat. Res. 1998; 149:517-520. [PubMed: 9588363]

15. Redpath JL, Liang D, Taylor TH, Christie C, Elmore E. The shape of the dose response curve for radiation-induced neoplastic transformation in vitro: Evidence for an adaptive response against neoplastic transformation at low doses of low-LET radiation. Radiat. Res. 2001; 156:700-707. [PubMed: 11741493]

16. Redpath JL, Lu Q, Lao X, Molloi S, Elmore E. Low doses of diagnostic energy X-rays protect against neoplastic transformation in vitro. Int. J. Radiat. Biol. 2003; 79:235-240. [PubMed: 12775447]

17. Ko SJ, Liao XY, Molloi S, Elmore E, Redpath JL. Neoplastic transformation in vitro after exposure to low doses of mammographic-energy $\mathrm{X}$ rays: Quantitative and mechanistic aspects. Radiat. Res. 2004; 162:646-654. [PubMed: 15548114] 
18. Azzam EI, de Toledo SM, Little JB. Direct evidence for the participation of gap junction-mediated intercellular communication in the transmission of damage signals from a-particle irradiated to nonirradiated cells. Proc. Natl. Acad. Sci. USA. 2001; 98:473-478. [PubMed: 11149936]

19. Mothersill C, Seymour CB. Cell-cell contact during gamma irradiation is not required to induce a bystander effect in normal human keratinocytes: Evidence for release during irradiation of a signal controlling survival into the medium. Radiat. Res. 1998; 149:256-262. [PubMed: 9496888]

20. Bauer G. Elimination of transformed cells by normal cells: a novel concept for the control of carcinogenesis. Histol. Histopathol. 1996; 11:237-255. [PubMed: 8720467]

21. Bauer G. Reactive oxygen and nitrogen species: efficient, selective, and interactive signals during intercellular induction of apoptosis. Anticancer Res. 2000; 20:4115-4139. [PubMed: 11205238]

22. Lyng FM, Seymour CB, Mothersill C. Production of a signal by irradiated cells which leads to a response in unirradiated cells characteristic of initiation of apoptosis. Br. J. Cancer. 2000; 83:1223-1230. [PubMed: 11027437]

23. Portess DI, Bauer G, Hill MA, O’Neill P. Low dose irradiation of non-transformed cells stimulates the selective removal of pre-cancerous cells via intercellular induction of apoptosis. Cancer Res. 2007; 67:1246-1253. [PubMed: 17283161]

24. Cregan SP, Brown DL, Mitchel REJ. Apoptosis and the adaptive response in human lymphocytes. Int. J. Radiat. Biol. 1999; 75:1087-1094. [PubMed: 10528915]

25. Davis TW, Wilson-Van Patten C, Meyers M, Kunugi KA, Cuthill S, Reznikoff C, Garces C, Boland CR, Kinsella TJ, Boothman DA. Defective expression of the DNA mismatch repair protein, MLH1, alters $\mathrm{G}_{2}-\mathrm{M}$ cell cycle checkpoint arrest following ionizing radiation. Cancer Res. 1998; 58:767-778. [PubMed: 9485033]

26. Le XC, Xing JZ, Lee J, Leadon SA, Weinfeld M. Inducible repair of thymine glycol detected by an ultrasensitive assay for DNA damage. Science. 1998; 280:1066-1069. [PubMed: 9582118]

27. Pant MC, Liao XY, Lu Q, Molloi S, Elmore E, Redpath JL. Mechanisms of suppression of neoplastic transformation in vitro by low doses of low LET radiation. Carcinogenesis. 2003; 24:1961-1965. [PubMed: 14514653]

28. Schöllnberger H, Mitchel REJ, Azzam EI, Crawford-Brown DJ, Hofmann W. Explanation of protective effects of low doses of $\gamma$-radiation with a mechanistic radiobiological model. Int. J. Radiat. Biol. 2002; 78:1159-1173. [PubMed: 12556343]

29. Redpath JL, Short SC, Woodcock M, Johnston PJ. Low-dose reduction in transformation frequency compared to unirradiated controls: the role of hyper-radiosensitivity to cell death. Radiat. Res. 2003; 159:433-436. [PubMed: 12600247]

30. Scott BR, Walker DM, Tesfaigzi Y, Schöllnberger H, Walker V. Mechanistic basis for nonlinear dose-response relationships for low-dose radiation-induced stochastic effects. Nonlin. Biol. Toxicol. Med. 2003; 1:93-122.

31. Scott BR. A biological-based model that links genomic instability, bystander effects, and adaptive response. Mutat. Res. 2004; 568:129-143. [PubMed: 15530546]

32. Brenner DJ, Little JB, Sachs RK. The bystander effect in radiation oncogenesis: II. A quantitative model. Radiat. Res. 2001; 155:402-408.

33. Nikjoo H, Khvostunov IK. Biophysical model of the radiation-induced bystander effect. Int. J. Radiat. Biol. 2003; 79:43-52. [PubMed: 12556330]

34. Little MP, Filipe JA, Prise KM, Folkard M, Belyakov OV. A model for radiation-induced bystander effects, with allowance for spatial position and the effects of cell turnover. J. Theor. Biol. 2005; 232:329-338. [PubMed: 15572058]

35. Sachs RK, Chan M, Hlatky L, Hahnfeldt P. Modeling intercellular interactions during carcinogenesis. Radiat. Res. 2005; 164:324-331. [PubMed: 16137206]

36. Schöllnberger H, Kotecki MR, Crawford-Brown DJ, Hofmann W, Eckl PM. Adaptive response and dose-response plateaus for initiation in a state-vector model of carcinogenesis. Int. J. Radiat. Biol. 1999; 75:351-364. [PubMed: 10203185]

37. Schöllnberger H, Stewart RD, Mitchel REJ, Hofmann W. An examination of radiation hormesis mechanisms using a multistage carcinogenesis model. Nonlin. Biol. Toxicol. Med. 2004; 2:317352. 
38. Schöllnberger H, Stewart RD, Mitchel REJ. Low-LET-induced radioprotective mechanisms within a stochastic two-stage cancer model. Dose Response. 2005; 3:508-518.

39. Joiner MC, Johns H. Renal damage in the mouse: The response to very small doses per fraction. Radiat. Res. 1988; 114:385-398. [PubMed: 3375433]

40. Crawford-Brown DJ, Hofmann W. A generalized state-vector model for radiation-induced cellular transformation. Int. J. Radiat. Biol. 1990; 57:407-423. [PubMed: 1968504]

41. Friedberg, EC. DNA Repair. Freeman, WH., editor. New York: 1985.

42. Little, JB. Cellular mechanisms of oncogenic transformation in vitro. In: Kakunaga, T.; Yamasaki, H., editors. Transformation Assay of Established Cell Lines: Mechanisms and Application. International Agency for Research on Cancer; Lyon: 1985. p. 9-29.IARC Scientific Publication No. 67

43. Sak A, Stuschke M. Repair of ionizing radiation induced DNA double-strand breaks (dsb) at the cmyc locus in comparison to the overall genome. Int. J. Radiat. Biol. 1998; 73:35-43. [PubMed: 9464475]

44. Broome EJ, Brown DL, Mitchel REJ. Adaptation of human fibroblasts to radiation alters biases in DNA repair at the chromosomal level. Int. J. Radiat. Biol. 1999; 75:681-690. [PubMed: 10404997]

45. Miller RC, Marino SA, Brenner DJ, Martin SG, Richards M, Randers-Pehrson G, Hall EJ. The biological effectiveness of radon-progeny alpha particles. II. Oncogenic transformation as a function of linear energy transfer. Radiat. Res. 1995; 142:54-60. [PubMed: 7899559]

46. Esinduy CB, Chang CC, Trosko JE, Ruch RJ. In vitro growth inhibition of neoplastically transformed cells by non-transformed cells: requirement for gap junctional intercellular communication. Carcinogenesis. 1995; 16:915-921. [PubMed: 7728974]

47. Bertram JS. Role of gap junctional cell/cell communication in the control of proliferation and neoplastic transformation. Radiat. Res. 1990; 123:252-256. [PubMed: 2217721]

48. Nagasawa H, Little JB. Bystander effect for chromosomal aberrations induced in wild-type and repair deficient CHO cells by low fluences of alpha particles. Mutat. Res. 2002; 508:121-129. [PubMed: 12379467]

49. Nelder JA, Mead R. A simplex method for function minimization. Computer J. 1965; 7:308-313.

50. Jürgensmeier JM, Schmitt CP, Viesel E, Höfler P, Bauer G. Transforming growth factor betatreated normal fibroblasts eliminate transformed fibroblasts by induction of apoptosis. Cancer Res. 1994; 54:393-398. [PubMed: 8275474]

51. Mendonca MS, Kurohara W, Antoniono R, Redpath JL. Plating efficiency as a function of time postirradiation: Evidence for the delayed expression of lethal mutations. Radiat. Res. 1989; 119:387-393. [PubMed: 2756124]

52. Stanbridge EJ, Wilkinson J. Analysis of malignancy in human cells: malignant and transformed phenotypes are under separate genetic control. Proc. Natl. Acad. Sci. USA. 1978; 75:1466-1469. [PubMed: 274733]

53. Schöllnberger H, Eckl PM. Protective bystander effects simulated with the State-Vector Model. Dose Response. 2007; 5:187-203. [PubMed: 18648609]

54. Wheeler KT, Nelson GB. Saturation of a DNA repair process in dividing and nondividing mammalian cells. Radiat. Res. 1987; 109:109-117. [PubMed: 3809385]

55. Miller RC, Geard CR, Martin SG, Marino SA, Hall EJ. Neutron-induced cell cycle-dependent oncogenic transformation of C3H 10T1² cells. Radiat. Res. 1995; 142:270-275. [PubMed: 7761576]

56. Mill AJ, Frankenberg D, Bettega D, Hieber L, Saran A, Allen LA, Calzolari P, FrankenbergSchwager M, Lehane MM, Tallone L. Transformation of C3H $10 \mathrm{~T}^{1} 1 / 2$ cells by low doses of ionising radiation: a collaborative study by six European laboratories strongly supporting a linear doseresponse relationship. J. Radiol. Prot. 1998; 18:79-100. [PubMed: 9656189]

57. Trosko JE, Chang CC, Madhukar BV. Modulation of intercellular communication during radiation and chemical carcinogenesis. Radiat. Res. 1990; 123:241-251. [PubMed: 2217720]

58. Trosko JE, Ruch RJ. Cell-cell communication in carcinogenesis. Front. Biosci. 1998; 3:d208-236. [PubMed: 9458335] 
59. Vral A, Cornelissen M, Thierens H, Louagie H, Philippe J, Strijckmans K, De Ridder L. Apoptosis induced by fast neutrons versus ${ }^{60} \mathrm{Co}$ gamma-rays in human peripheral blood lymphocytes. Int. J. Radiat. Biol. 1998; 73:289-295. [PubMed: 9525257]

60. Fujikawa K, Hasegawa Y, Matsuzawa S, Fukunaga A, Itoh T, Kondo S. Dose and dose-rate effects of $\mathrm{X}$ rays and fission neutrons on lymphocyte apoptosis in $\mathrm{p} 53^{+/+}$and $\mathrm{p} 53^{-/-}$mice. J. Radiat. Res. (Tokyo). 2000; 41:113-127. [PubMed: 11037579]

61. Boreham DR, Dolling JA, Maves SR, Siwarungsun N, Mitchel RE. Dose-rate effects for apoptosis and micronucleus formation in gamma-irradiated human lymphocytes. Radiat. Res. 2000; 153:579-586. [PubMed: 10790279]

62. Jamali M, Trott KR. Persistent increase in the rates of apoptosis and dicentric chromosomes in surviving V79 cells after X-irradiation. Int. J. Radiat. Biol. 1996; 70:705-709. [PubMed: 8980668]

63. Ponnaiya B, Jenkins-Baker G, Bigelow A, Marino S, Geard CR. Detection of chromosomal instability in alpha-irradiated and bystander human fibroblasts. Mutat. Res. 2004; 568:41-48. [PubMed: 15530538]

64. Little JB, Nagasawa H, Li GC, Chen DJ. Involvement of the nonhomologous end joining DNA repair pathway in the bystander effect for chromosomal aberrations. Radiat. Res. 2003; 159:262267. [PubMed: 12537532]

65. Nagasawa H, Peng Y, Wilson PF, Lio YC, Chen DJ, Bedford JS, Little JB. Role of homologous recombination in the alpha-particle-induced bystander effect for sister chromatid exchanges and chromosomal aberrations. Radiat. Res. 2005; 164:141-147. [PubMed: 16038585]

66. Kemp LM, Sedgwick SG, Jeggo PA. X-ray sensitive mutants of Chinese hamster ovary cells defective in double-strand break rejoining. Mutat. Res. 1984; 132:189-196. [PubMed: 6513971]

67. Schöllnberger H, Mitchel REJ, Crawford-Brown DJ, Hofmann W. A model for the induction of chromosome aberrations through direct and bystander mechanisms. Radiat. Prot. Dosimetry. 2006; 122:275-281. [PubMed: 17166875]

68. Scott BR. A mechanistic model for neoplastic transformation of cells by high LET radiation and its implications for low dose, low dose rate, risk assessment. Radiat. Prot. Dosimetry. 1997; 72:105117.

69. Schöllnberger H, Scott BR, Hanson TE. Application of Bayesian inference to characterize risks associated with low doses of low-LET radiation. Bull. Math. Biol. 2001; 63:865-883. [PubMed: 11565407]

70. Scott BR, Walker DM, Walker VE. Low-dose radiation and genotoxic chemicals can protect against stochastic biological effects. Nonlin. Biol. Tox. Med. 2001; 2:185-211.

71. Belyakov OV, Mitchell SA, Parikh D, Randers-Pehrson G, Marino SA, Amundson SA, Geard CR, Brenner DJ. Biological effects in unirradiated human tissue induced by radiation damage up to 1 mm away. Proc. Natl. Acad. Sci. USA. 2005; 102:14203-14208. [PubMed: 16162670] 


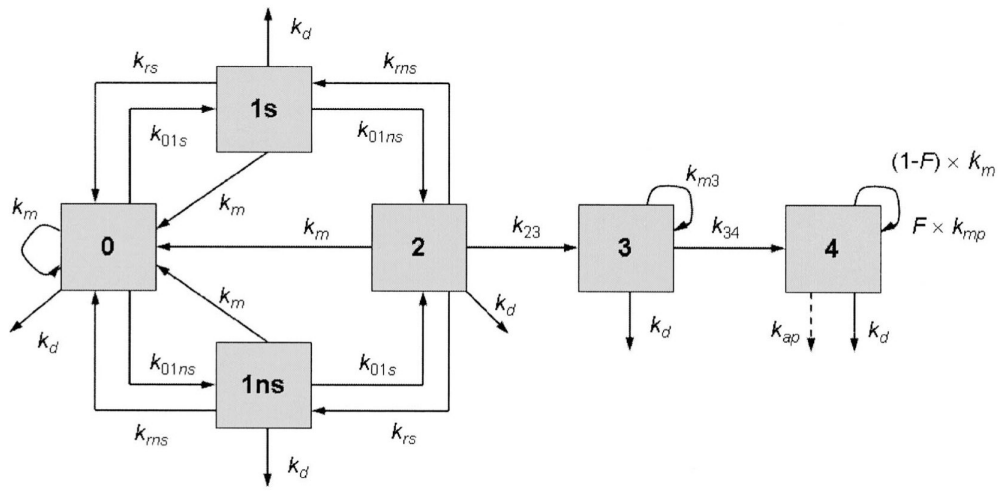

FIG. 1.

Pictorial representation of the State-Vector Model. State 4 cells can be eliminated by a doserate-independent protective apoptosis-mediated bystander effect ( $k_{a p}$, dashed arrow) in addition to the dose-rate-dependent pathway for cell killing by necrosis $\left(k_{d}\right)$. Rate constant $k_{a p}$ is applied only in the fit of the data of Redpath et al. (15) for immediate and delayed plating. 

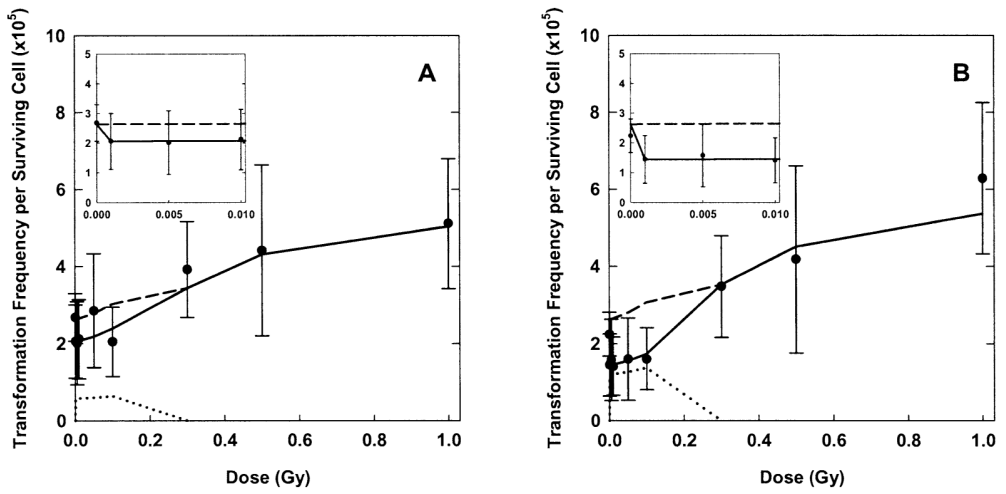

FIG. 2.

Transformation frequency for CGL1 cells irradiated with $\gamma$ radiation (15). Error bars represent $95 \%$ confidence intervals. Panel A: Data for immediate plating and SVM fit showing the three different contributions $[(---)$ direct, $(\cdots \cdots)$ bystander, $(-)$ total (fit2)]. The direct contribution stems from a forward simulation of the model without PAM with parameter values from fit1. The contribution of the bystanders was calculated as the difference between the forward simulation and fit2. Panel B: data for delayed plating and SVM fit showing the three different contributions $[(---)$ direct, $(\cdots \cdots)$ bystander, $(-)$ total (fit4)]. Insets show the low-dose range with the $x$-axis units in Gy. 

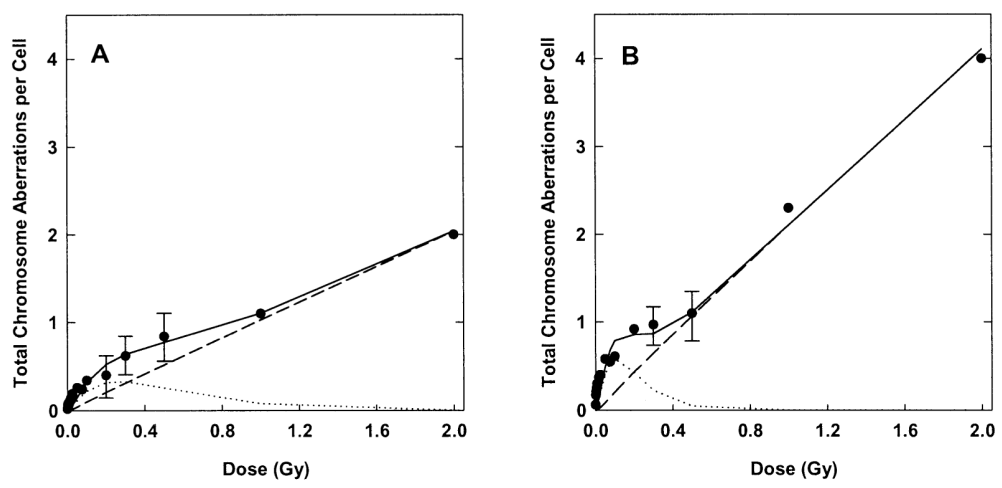

FIG. 3.

Chromosomal aberrations as a function of mean dose of a-particle radiation (48). Panel A: Data for wild-type CHO cells and SVM fits showing the three different contributions [--direct (fit6), $(\cdots \cdots)$ ) bystander, (- total (fit7)]. The contribution of the bystanders was calculated as the difference between fit7 and fit6. Panel B: Data for xrs-5 cells and SVM fits showing the three different contributions $[(---)$ direct (fit8), $(\cdots \cdots)$ bystander, $(-)$ total (fit9)]. The data points represent mean values \pm standard deviations (48). 


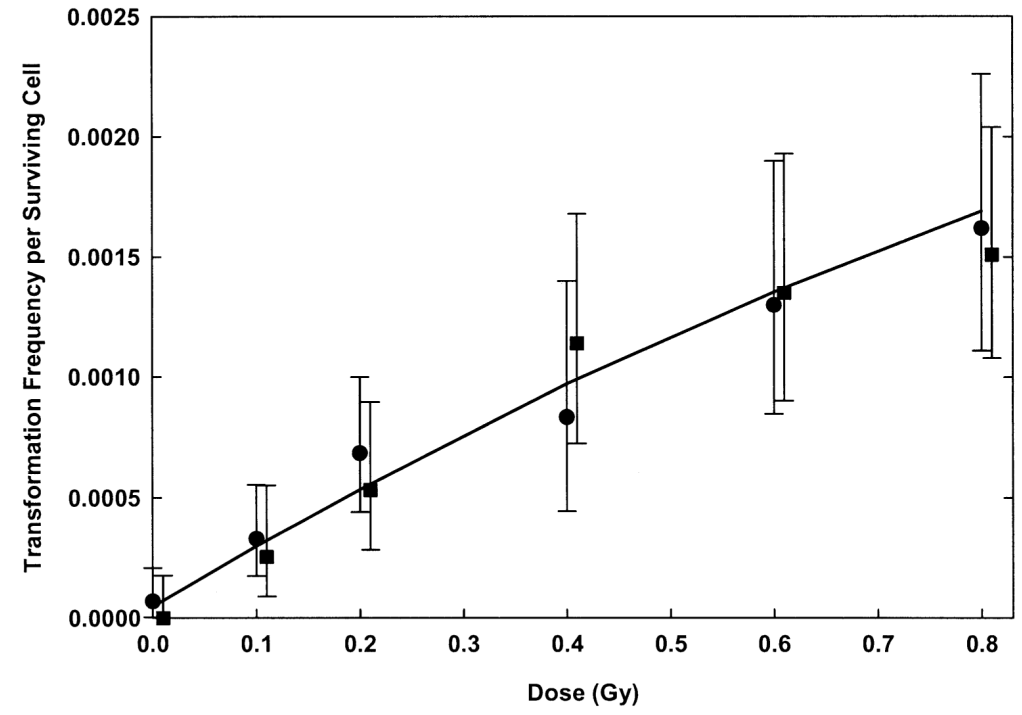

FIG. 4.

Transformation frequency after exposure of C3H $10 \mathrm{~T} 1 / 2$ cells to $150 \mathrm{keV} / \mu \mathrm{m}$ a particles (45). (O) First subset, (ם) second subset. Error bars represent $95 \%$ confidence intervals. (—) fit10. Bystander effects were not included in the model. 


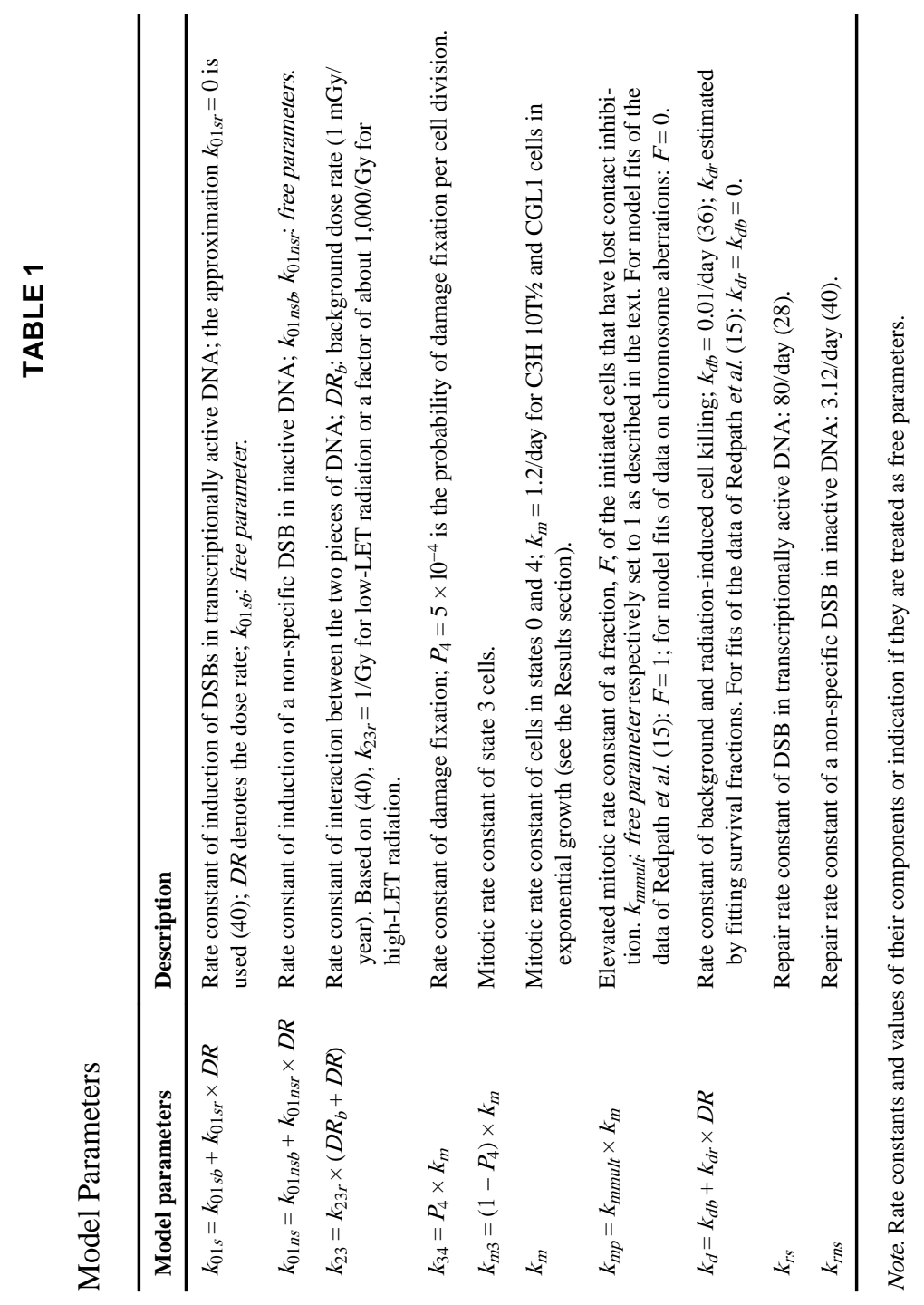

Radiat Res. Author manuscript; available in PMC 2011 May 05. 


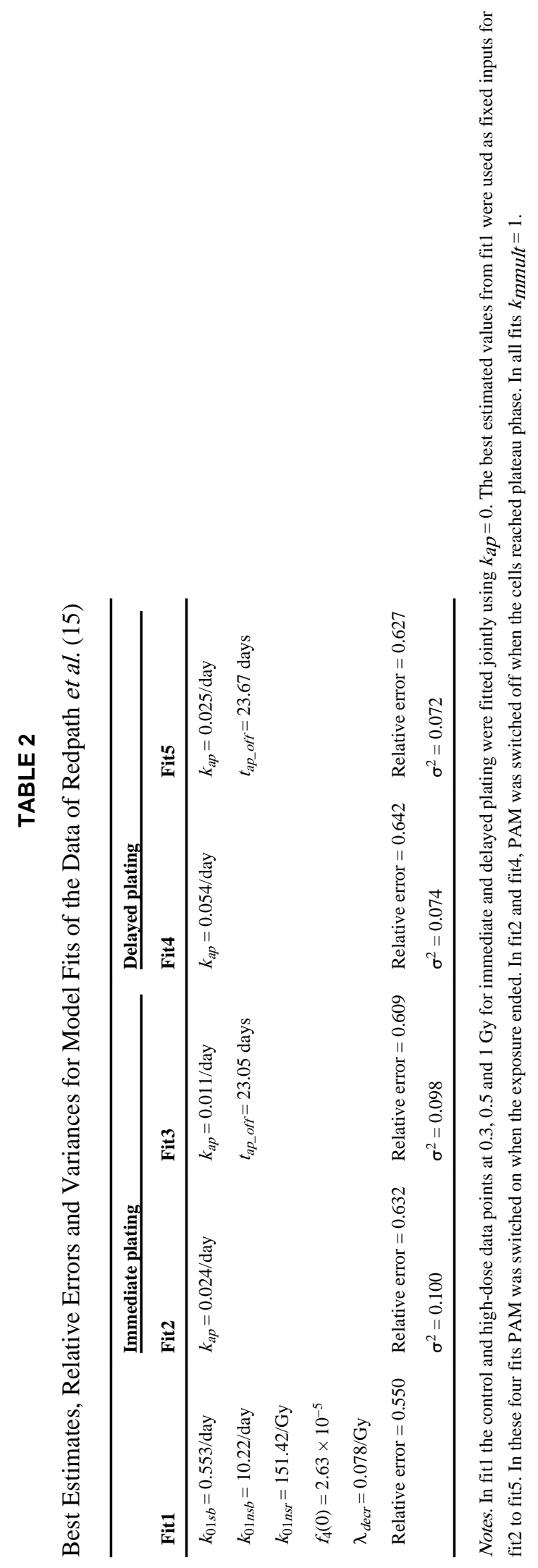

Radiat Res. Author manuscript; available in PMC 2011 May 05. 


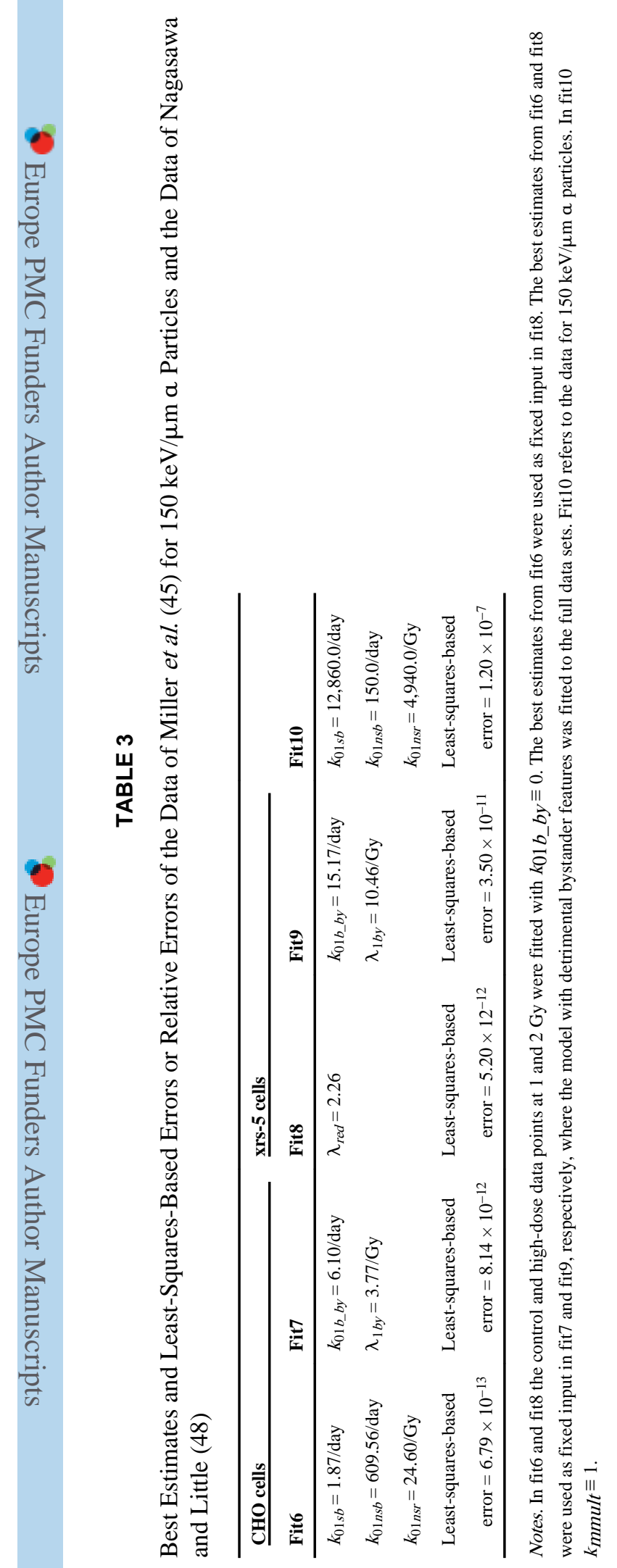

Radiat Res. Author manuscript; available in PMC 2011 May 05. 